\title{
Illness Narrative: Perceptions and Lived Experiences of Kidney Recipient Clients in Shanghai, China
}

\author{
Nathan B. W. Chimbatata1,2, Chao Hu ${ }^{3}$ \\ ${ }^{1}$ School of Public Health, Fudan University, Shanghai, China \\ ${ }^{2}$ Mzuzu University, Mzuzu, Malawi \\ ${ }^{3}$ Department of Urology, Fudan University, Shanghai, China \\ Email: natchims@yahoo.com
}

How to cite this paper: Chimbatata, N.B.W. and Hu, C. (2016) Illness Narrative: Perceptions and Lived Experiences of Kidney Recipient Clients in Shanghai, China. Open Journal of Nephrology, 6, 67-77. http://dx.doi.org/10.4236/ojneph.2016.63009

Received: August 24, 2016

Accepted: September 16, 2016

Published: September 19, 2016

Copyright $\odot 2016$ by authors and Scientific Research Publishing Inc. This work is licensed under the Creative Commons Attribution International License (CC BY 4.0).

http://creativecommons.org/licenses/by/4.0/ cC) (i) Open Access

\begin{abstract}
Terminal kidney disease is a life threatening condition and cause for loss of hope to affected individuals. It affects the individuals physically as well as mentally. The advancement in medical knowledge and technology in transplant surgery has steadily increased the number of kidney recipients. This offers hope for the new lease of life and a wide range of perceptions and experiences with self, society and the new organ. There is minimal research on perceptions and lived experiences of kidney transplant recipients. This study explored the perceptions and lived experiences of individuals with a kidney problem living with a kidney transplant in Shanghai, China. Five indepth interviews were conducted with five clients. The participant's age ranged from 25 to 45 years. There were three females and two males. Content analysis using NVivo (11.0) software was applied in data analysis. The findings revealed improved quality of life among kidney recipients; however the clients had low knowledge levels on the condition as well as self care practices in the post transplant period. This caused a lot of psychosocial stress in the clients. The post kidney transplant management strategies should include effective education programs to increase awareness on the condition and self care practices so as to reduce factors associated with psychosocial stress in order to improve the quality of life for the clients in the post kidney transplantation period.
\end{abstract}

\section{Keywords}

Kidney Transplant, Psychosocial Stress, Perceptions, Lived Experiences, Shanghai, China 


\section{Introduction}

Kidney disease is a life threatening condition that subjects affected individuals to a challenging life experience. Chronic kidney disease (CKD) is a situation whereby there is a reduced glomerular filtration rate, increased urinary albumin excretion, or both [1]. The global prevalence of CKD is estimated to be around $8 \%-16 \%$. Around $10 \%$ of the global population is affected by CKD and millions die every year because of the unavailability of affordable treatment [2]. It is commonly associated with diabetes mellitus and in some settings causes such as herbal and environmental toxins are common. If it is left unattended to, CKD has severe lifelong complications that include cardiovascular problems, kidney injury, decline in cognitive function, risk of anaemia, bone disorders i.e. fractures and end stage renal disease (ESRD) [1]. Patients suffering from this condition face long time treatment related stressors. The recent advancement in medical knowledge and technology has made kidney transplant the most desirable remedy for patients with renal failure. Though kidney transplant is thought to improve the quality of life among the recipients, it brings with it new challenges and changes in life styles. Patients could live with persistent fear of organ rejection and compliance to life long course of treatment [3]. The patients often need to cope with changes in their concept of self, confidence and a change in family roles that the transplant procedure brings. These changes could affect the patient as a holistic person and affect their perceptions and lived experiences in the new lease of life [4].

Studies show significant improvement in the quality of life among kidney transplant recipients. The improvement in the quality of life is even more satisfying if the recipients return to their normal official duties [5]. However, the post transplant period brings a lot of stress in the recipient patients and health care professionals are required to understand the perceptions and lived experiences of patients living with kidney transplant in order to adequately handle their social, physical and emotional concerns. By acquiring such insights, health care professionals can implement relevant strategies that can bring significant improvement in the quality of life for the patients.

This qualitative study was therefore set out to explore the perceptions and lived experiences of kidney recipient patients in Shanghai, China.

\section{Methodology}

\subsection{Study Design}

The study was a qualitative one and mainly utilized phenomenological approach. This qualitative study used in-depth interview approach to interview kidney recipient clients in order to gain in-depth understanding of their perceptions and lived experiences in the post transplant period. The design was appropriate for the study because its purpose was to describe the perceptions and lived experiences of the kidney recipient participants [6].

\subsection{Study Setting}

The study was conducted in Shanghai, China. A renal department at one of the tertiary hospitals formed the study site. 


\subsection{Study Participants}

The participants were identified through purposive sampling by the health care worker who was attending to them during the clinic review visits. The participants were briefed about the study and voluntarily consented to participate in the in-depth interviews. A total of 5 kidney recipient patients participated in the study.

\subsection{Inclusion and Exclusion Criteria}

The study recruited participants who had lived with a kidney transplant for a period of one year or more and those who lived with a transplant less that a minimum period of a year were excluded. The participants were supposed to be clinically stable and those not clinically stable were excluded as well. The participants who refused to give consent for participation were also not included in the study.

\subsection{Data Collection}

Five in-depth interviews were conducted. Prior to each interview session, the study participant was provided a guide on the process of the interview and informed consent was obtained. All the interview sessions were audio recorded and each session of the interview lasted 25 to 35 minutes on average. The questions for the interview surrounded patient perceptions and lived experiences living with a transplant. Facilitation of the interviews was through active listening, paraphrasing and probing when required was also utilized.

\subsection{Data Analysis}

Data was analyzed using Nvivo soft ware. The researcher and assistant researcher listened to the recorded interview sessions and the interviews were transcribed verbatim. Repetitive reading of transcribed data lead to code development and then data categories were grouped and major themes were developed. The transcripts were shared with another independent researcher to separately come up with the codes. Differences that emerged were discussed and resolved.

\subsection{Ethical Clearance}

Ethical clearance was obtained from department of medical anthropology Fudan University and the hospital management and renal department at the site of the study. The participants were given details of the study prior to their participation and informed consent was obtained. They were given the freedom to take part and were free to withdraw at any time without any penalty. The principles of autonomy and anonymity were upheld throughout the study and no participant's identifiers were to be attached in research documents and publication reports.

\section{Findings}

\subsection{Characteristics of the Study Participants}

The study included clinically stable kidney recipient clients. There were five clients in 
total, their ages ranged from 25 to 45 years. There were 3 females and 2 males altogether and the participants had lived with the kidney transplant for a period of a year to nine years. They were all working or business class people.

\subsection{Themes}

The findings revealed overall improved quality of life among recipients and that kidney transplant patients under go vast experiences and life adjustments post kidney transplantation procedure. The findings indicated that kidney recipients are subjected to a lot of psychosocial stress with the kidney terminal disease and as they live with the new organ in the post transplantation period. The main findings have been summarized under two predetermined themes and several sub themes. The major themes are psychosocial stress and client lived experiences.

\subsubsection{Psychosocial Stress}

The findings revealed that all the participants experienced some levels of stress from the onset of symptoms of the condition to post kidney transplantation period. The symptoms which were experienced prior to the diagnosis of the problem included headache, fatigue, shortness of breath, poor appetite, sleeplessness and high blood pressure. All the participants indicated that they did not know these as the symptoms of kidney disease;

No clear meaning, just knew it is a disease. (Female, 32 years)

And;

Not special. I did not know. (Male, 25 years)

\subsubsection{Activity before Seeking Medical Care}

The findings showed that most of the participants did not know what to do when they saw the symptoms. This could be one of the factors for the stress that they experienced. The participants' excerpts on this included;

I did nothing, but I visited several hospitals before I was told that I have a chronic kidney disease. (Female, 32 years)

Another one added;

I sought advice from a relative who is a doctor. (Female, 36 years)

Another participant further stated that she sought care from traditional Chinese hospital;

I visited traditional Chinese medicine hospitals for two years. I have been receiving herbals and I hope it helped quite well. (Male, 33 years)

One participant hinted that he thought had a disease of the stomach and visited several hospitals before he was told of the kidney problem;

I thought it was a disease of the stomach. I visited several hospitals and at one hospital they transferred me to cardiac department then it was found that I have a problem with kidney and I underwent dialysis. (Male, 25 years)

\subsubsection{Causes of the Problem}

The findings showed that the participants had mixed views/perceptions on the causes 
of their condition. The participants said;

Genetic deformity disease because my mum also had it (Female, 32 years)

Another participant added;

I just think could be irregular sleep pattern, new house and toxins from furniture and environment as well as new house pollution. (Female, 45 years)

Two of the participants thought that their kidney problem was due to prematurity and they had the following excerpts;

I was a premature child with low birth weight, no breast milk. I always had a condition of anaemia, easily attacked by other diseases and thought this could be related to renal problem. (Male, 33 years)

And;

I was born prematurely with low birth weight. I always eat roasted food, nodules three to four times a week. (Male, 25 years)

\subsubsection{Feelings of Being Responsible for the Problem}

The findings revealed that the majority of kidney recipient clients thought they were responsible for the problem. This could have increased their levels of stress and the clients had the following excerpts on this;

In Shanghai a lot of pressure, pressure of work, I could skip my diet. Some signals I ignored them which I think could be related to my problem. (Male, 33 years)

And another participant said;

I feel responsible for the problem; I eat a lot of roasted food. (Male, 25 years)

Another one was skeptical on whether was responsible for the problem;

Maybe, because of my life style and the environment I was living in. (Female, 45 years)

\subsubsection{Problem Seriousness}

The findings showed that the majority of the clients perceived the problem as very serious and this subjected them to a lot of stress. The clients' excerpts were;

It's a terrible, very serious condition; usually I had high blood pressure and heart failure. (Male, 33 years)

And another added;

It is very serious, I cannot sleep well at night. I just went to hospital and obeyed the prescription. (Male, 25 years)

One participant emphatically stated that she was very puzzled realizing she had the condition;

Very serious and I was puzzled, just went to hospital. (Female, 45 years)

\subsubsection{Effect of Problem on Body and Mind}

The participants were asked to describe the effect of the condition on their body and mind. Some participants perceived it as a source of sadness and caused them to lose concentration. This greatly affected their personal sense of self;

Sadness, I thought it was unacceptable and very sad. (Female, 32 years)

Another client stated; 
No concentration, no innovation, I do not have any zeal to do things. (Male, 25 years)

The other participant also added that the problem made her lose hope;

Grey day, it brought grey day experience, no hope and no energy to do things. (Female, 45 years)

\subsubsection{Meaning of the Diagnosis}

The knowledge of the diagnosis brought a lot of anxiety in the clients. The findings showed that the participants experienced a sense of denial and helplessness upon the knowledge of the diagnosis;

Sadness, felt like the sky is falling down on me. It was unacceptable, I did not accept it. I thought it was dangerous, I felt it would take my life. I did not worry about the treatment since the side effects of the treatment could be controlled. I got my kidney from my father and I am worried about him, I have to work and support the family. (Female, 32 years)

And another;

Unacceptable, I had to undergo attitude adjustment and without excuses had to accept it and see how to treat it. (Male, 33 years)

The other client stated that to her the meaning was that she will be a dependent person as she will not be able to work because of the problem;

To me the meaning was no work anymore because I was feeling too tired. (Female, 45 years)

Another client also reported instances of stigma, so to such clients the diagnosis meant stigmatization in society;

I got a job and the company abandoned me because of stigma and for me to get another job it is problematic. I also fear death and drug side effects though I feel side effects will be managed by doctors. (Male, 25 years)

\subsection{Lived Experiences}

The findings showed that the clients had varying reactions and treatment of the new organ and that most of them experienced financial problems in meeting the cost of the treatment;

Cost of treatment is very expensive. (Female, 32 years)

Another client added;

Treatment is very expensive, but I am trying. (Male, 33 years)

Furthermore another one stressed;

Expensive, treatment is expensive. (Male, 25 years)

\subsubsection{Reaction to New Organ and Treatment of New Organ}

The findings revealed that the clients reacted differently to the new organ. Majority of the clients described getting a new organ as a cherishable experience;

Cherish, treasure it. I regard it as a treasure and cherish it very much. I use hands to shield and protect it. I have a prudent attitude regarding the care of my new kidney. (Female, 32 years) 
And another stated;

I cherish it very much. I knew the new kidney will give me new life. I visit the clinic monthly to check on my kidney function. The advice is once in three months. (Female, 36 years)

And another further added;

Surprise, I cherish it very much, very important for me to live and I did not wait to come to hospital for the operation. I treasure it so much. (Female, 45 years)

However, one participant, contrary to what the majority stated, described getting a new organ as an unacceptable experience;

Unacceptable, did not want it, I got it from my mum after discussions because I was refusing it. It was like she was giving birth to me for the second time. I protect it, no compression and regularly taking medications without stopping to avoid trauma to the new organ. (Male, 25 years)

\subsubsection{Lived Experiences with New Organ}

The participants acknowledged that with the new organ life was not the same any more. It had a lot of restrictions in order to safe guard the transplant. However, the majority of the participants reported improved quality of life with the new organ;

I am not tired any more. I am more and more active than before. (Female, 36 years)

And another stated;

A little improvement, Diet habit has changed; more meat less vegetables, chicken and duck. (Male, 33 years)

Another client stressed on the improved quality of life;

My life has changed a lot, I sleep peacefully, no more overworking. My diet has changed; more vegetables and I do more exercise-walking. (Male, 25 years)

One participant stated that she was now living a normal life with the new organ;

Now normal life, I am much healthier than before, much more regular and I do exercises. (Female, 45 years)

\subsubsection{Shared Experience}

The participants were asked to share their lived experiences outside the hospital clinic setting when they are in their society on how they take care of themselves. Majority of the clients reported that they are in social net work groups where they discuss and share information regarding their problem;

I am in a kidney recipient group where results are communicated and the doctor gives advice. I am also in a wechat group where we communicate and share a lot of information regarding our condition. (Female, 32 years)

Another participant added that he has a plan to increase public awareness of kidney disease and he had the following excerpt;

Not only to share but I have a business proposal to develop a public software to spread the kidney disease messages by myself including funding the project. I developed a group club of patients who have undergone kidney transplant procedure. The results are sent to the group and there is a doctor for advice. (Male, 33 years) 


\section{Discussion}

Quality of life for recipients in the post kidney transplant period is subjected to a lot of psychosocial stress [3]. A number of factors influenced stress in the current study and they included lack of knowledge on the condition, thoughts of being sorry for the relative kidney donor, un affordability of available treatment, drug side effects, adjustment of the personal self and blame for the self as well as the feelings of being responsible for the kidney loss.

The clients living with a transplant experience new challenges in the post transplant period, such challenges include a span of chronic infections, life course of complex medications and fear of death [7]. These challenges demand that these clients should acquire knowledge on their condition in order to effectively take good care of self in the post transplantation period.

This current study reflected a gross lack of knowledge of the condition among the clients from the conception of condition symptoms as well as in the post transplantation period. This lack of knowledge in the pre surgical period may have caused a lot of anxiety in the clients as they were victims of fear of unknown. This calls for effective education strategies to improve public awareness of chronic kidney disease. It is also recommended that the patients who have undergone kidney transplantation procedure should be exposed to effective education regarding their self care in the post transplantation period.

The study also revealed lack of knowledge on health promotion activities in the post transplantation period. The clients in this study had low levels of knowledge of self care practices such as monitoring of vital signs, dietary adjustment (low salt diet), regular exercises, good hydration status and realization of potential risks of infections. This poor knowledge would mean that the patients self management in the post transplant period was full of inadequacies. However, the findings revealed that the participants were adherent to drugs, which was good in preventing infections but this needed to be complimented with good and efficient self care practices. Inadequate self care practices among kidney recipient clients have also been reported in other studies. In a study by Gordon et al. 2009 [8], to explore self care strategies and barriers among kidney transplant recipients, it was found that few kidney recipient patients followed optimal self care practices regarding personal hydration and physical exercise. It was also reported in this study that most of the patients faced challenges on self care, one of them being that they were not sternly advised to do so by the health care providers. Similarly another study also found lack of knowledge on self care after kidney transplantation as a main factor that affected patient outcomes in the post transplantation period [9].

The findings also revealed that the main sources of stress were poor knowledge on the condition, feelings of self blame on the cause of the problem, denial of the diagnosis, perceived severity of the problem, cost of treatment, medication side effects as well as the fear of loss of life due to the problem. This meant that the psychosocial stress that the clients experienced mainly originated from the lack of knowledge on the condition and lack of knowledge on self care practices. The individual participants described the 
ways which they used to reduce levels of stress such as not thinking too much about the problem, sticking to the doctor's prescription, drug adherence and by joining social network groups and sharing information regarding their problem. Similarly, it was observed in another study that the participants coped with stress by blocking thoughts regarding their illness [10]. What the participants outlined in the current study on stress management lacked content on effective self care practices. This therefore calls for immediate implementation of effective awareness strategies in order to mitigate this knowledge gap to significantly reduce the levels of psychosocial stress among the clients and maximize good patient outcomes. In a study by Orr et al. 2007, [11], fear was also found to be a main source of stress. The kidney recipient clients despite experiencing a considerable improvement in the quality of life, they experienced strong fear that the new kidney would fail at some point. This made them to perceive eminent death rooming and it is reported in the same study that clients were prepared for this tragic moment. In another study conducted in Norway, kidney recipient clients described kidney transplantation as a turning point in life that brought severe learning difficulties because of high levels of both physical and mental stress. The clients in the study expressed the need for a supportive learning atmosphere with continued learning as critical to a successful post transplantation period [12].

Literature has shown significant improvement in the quality of life for kidney transplant patients [5] [13]. Similarly, in this current study all the participants indicated great improvement in the quality of life in the post transplantation period though this improvement was individual based. Majority of the participants stated that their life was now healthier than before and that they were more active than before. They described their status as a cherishable situation and that the new kidney has given them new hope and new chance to live again in the new lease of life;

I cherish, treasure the new kidney. I regard it as a treasure and cherish it very much. I use hands to shield and protect it, I have a prudent attitude regarding the care of my new kidney. (Female, 32 years)

And another participant stated;

I am not tired any more. I am more and more active than before. (Female, 36 years)

However, the improvement in the quality of life among the clients did not have a parallel rise in self awareness regarding effective self care practices so that it could be realized to its maximum potential.

\section{Study Limitation}

The interviews were conducted in a mixture of Chinese and English languages. This may have affected the richness of the data as data may have been lost during transcription however the recordings were supplemented with the notes taken during the indepth interviews.

\section{Conclusion}

The findings highlighted some useful insights regarding perceptions and the lived ex- 
periences of kidney recipient patients. Though all the participants reported improved quality of life in the transplantation period, the findings revealed participants' low levels of knowledge on their condition and self care practices in the post transplant period. This subjected the participants to a multitude of psychosocial stress. Therefore, there is a need to implement effective patient education programs to improve patient awareness on the problem and improve awareness on self care practices among the recipients. The failure to do so would subject the recipients to enormous psychosocial stress thereby negatively impacting on the quality of life in the post transplant period [14]. Further research is recommended to explore the perceptions and lived experiences in the long time transplant recipients. Studies should also be conducted to explore the effectiveness of education strategies used for teaching the transplant recipients.

\section{Acknowledgements}

We would like to thank all the kidney recipient clients who participated in this study.

\section{Conflict of Interest}

There is no conflict of interest involved in this study.

\section{References}

[1] Vivekanand, J., Guillermo, G.G., Kunitoshi, I., Zuo, L., Saraladevi, N., et al. (2013) Chronic Kidney Disease: Global Dimension and Perspectives. Lancet, 382, 260-272. http://dx.doi.org/10.1016/S0140-6736(13)60687-X

[2] (2015) World Kidney Day: Chronic Kidney Disease. http://www.worldkidneyday.org/faqs/chronic-kidney-disease/

[3] Kamran, F. (2014) Living with a Kidney Transplant: Perceptions and Experiences. American Journal of Applied Psychology, 2, 5-12.

[4] Bayhakki and Hatthakit, U. (2012) Lived Experiences of Patients on Hemodialysis: A Metasynthesis. Nephrology Nursing Journal, 39, 295-304.

[5] Overbeck, I., Bartels, M., Decker, O., Harms, J., Hauss, J. and Fangmann, J. (2005) Changes in Quality of Life after Renal Transplantation. Transplantation Proceedings, 37, 1618-1621. http://dx.doi.org/10.1016/j.transproceed.2004.09.019

[6] Polit, D.F. and Beck, C.T. (2008) Essentials of Nursing Research, Methods, Appraisals and Utilization. 5th Edition, Lippincott, New York.

[7] Luk, W.S.C. (2004) The HRQoL among Renal Transplant Patients. Journal of Clinical Nursing, 13, 201-209. http://dx.doi.org/10.1046/j.1365-2702.2003.00867.x

[8] Gordon, E.J., Prohaska, T.R., Gallant, M. and Siminoff, L.A. (2009) Self-Care Strategies and Barriers among Kidney Transplant Recipients: A Qualitative Study. Chronic Illness, 5, 75. http://dx.doi.org/10.1177/1742395309103558

[9] Skiveren, J., Mortensen, E.L. and Haedersdal, M.J. (2010) Sun Protective Behaviour in Renal Transplant Recipients. A Qualitative Study Based on Individual Interviews and the Health Belief Model. Dermatology Treatment, 21, 331-336. http://dx.doi.org/10.3109/09546630903410166

[10] de Guzman, A.B., Chy, M.A.S., Concepcion, A.F.P., Conferido, A.J.C. and Coretico, K.I. (2009) The Language of Coping: Understanding Filipino Geriatric Patients' Hemodialysis 
Lived Experiences. Educational Gerontology, 35, 769-783.

http://dx.doi.org/10.1080/03601270802708384

[11] Orr, A., Willis, S., Holmes, M., Britton, P. and Orr, D. (2007) Living with a Kidney Transplant: A Qualitative Investigation of Quality of Life. Journal of Health Psychology, 12, 653662. http://dx.doi.org/10.1177/1359105307078172

[12] Urstad, K.H., Wahl, A.K., Andersen, M.H., Øyen, O. and Fagermoen, M.S. (2012) Renal Recipients' Educational Experiences in the Early Post-Operative Phase-A Qualitative Study. Scandinavian Journal of Caring Sciences, 26, 635-642. http://dx.doi.org/10.1111/j.1471-6712.2012.00972.x

[13] Wiederhold, D. (2008) Quality of Life and Subjective Experiences after Kidney Transplantation: Quantitative and Qualitative Research. Dialyse Aktuell, 12, 82-92. http://dx.doi.org/10.1055/s-2008-1077105

[14] Murpy, F. (2007) The Role of the Nurse Postrenal Transplantation. British Journal of Nursing, 16, 667-675. http://dx.doi.org/10.12968/bjon.2007.16.11.23689

Submit or recommend next manuscript to SCIRP and we will provide best service for you:

Accepting pre-submission inquiries through Email, Facebook, LinkedIn, Twitter, etc. A wide selection of journals (inclusive of 9 subjects, more than 200 journals) Providing 24-hour high-quality service User-friendly online submission system Fair and swift peer-review system Efficient typesetting and proofreading procedure Display of the result of downloads and visits, as well as the number of cited articles Maximum dissemination of your research work

Submit your manuscript at: http://papersubmission.scirp.org/ 